\title{
Huachansu mediates cell death in non-Hodgkin's lymphoma by induction of caspase-3 and inhibition of MAP kinase
}

\author{
EKEM T. EFUET, XIAO-PING DING, CARRIE CARTWRIGHT, \\ YONG PAN, LORENZO COHEN and PEIYING YANG
}

\author{
Department of General Oncology, Integrative Medicine Program, \\ The University of Texas MD Anderson Cancer Center, Houston, TX 77030, USA
}

Received January 24, 2015; Accepted March 9, 2015

DOI: 10.3892/ijo.2015.3044

\begin{abstract}
Huachansu (HCS), a hot water extract of the skin glands of Bufo gargarizans (B. melanostictus), has been used extensively in the treatment of various solid tumors in Asia, particularly in China. However, its effect on the growth of malignancies of hematopoietic origin, particularly lymphomas, is limited. Here we investigated the antiproliferative effect and molecular mechanisms of HCS using non-Hodgkin's lymphoma (NHL) Raji, Ramos, and Namalwa cells and the mantle cell lymphoma cells SP53. HCS inhibited proliferation in these cell lines with an $\mathrm{IC}_{50}$ ranging from 3.1 to $25 \mu \mathrm{l} / \mathrm{ml}$. At a concentration of $25 \mu \mathrm{l} / \mathrm{ml}$, HCS triggered a sub-G1 arrest in Ramos cells and induced early to late apoptotic cell death. Cleaved caspase-3 was formed in a concentration-dependent manner in Ramos cells following treatment with HCS for $24 \mathrm{~h}$. Intriguingly, when the Ramos cells were treated with the caspase inhibitor ZDEVD, the apoptotic activity of HCS was partially blocked. Furthermore, HCS also blocked the expression of survivin and $\mathrm{pRB}$ proteins in a concentration-dependent
\end{abstract}

Correspondence to: Dr Peiying Yang, Department of General Oncology, Integrative Medicine Program, The University of Texas, MD Anderson Cancer Center, 1515 Holcombe Blvd., Unit 462, Houston, TX 77030, USA

E-mail: pyang@mdanderson.org

Abbreviations: HCS, Huachansu; NHL, non-Hodgkin's lymphoma; BL, Burkitt's lymphoma; MCL, mantle cell lymphoma; TCM, traditional Chinese medicine; VEGF, vascular endothelial growth factor; EGFR, epidermal growth factor receptor; MAPK, mitogenactivated protein kinase; ZDEVD, benzyloxycarbonyl-Asp-Glu-ValAsp-fluoromethylketone; DMSO, dimethyl sulfoxide; PI, propidium iodide; PBMC, peripheral blood mononuclear cell; FBS, fetal bovine serum; FACS, fluorescence-activated cell-sorting analysis; FITC, fluorescein isothiocyanate; HEPES, $N$-2-hydroxyethylpiperazine$N$ '-2-ethanesulfonic acid; EDTA, ethylenediaminetetraacetic acid; SDS-PAGE, sodium dodecyl sulfate-polyacrylamide gel electrophoresis; TEM, transmission electron microscopy

Key words: Huachansu, non-Hodgkin's lymphomas, apoptosis, caspase, MAP kinase manner in Ramos cells. Mechanistically, HCS downregulated both the MAPK gene and proteins in Ramos cells. Collectively, our data suggest that HCS is effective in inducing cell death and apoptosis, in part, by activating caspase-3 activity and suppressing MAP kinase in NHL cells.

\section{Introduction}

Non-Hodgkin's lymphomas (NHLs) are common hematologic malignancies representing $\sim 5.3 \%$ of all cancers in the United States and $>50 \%$ of all blood cancers (1). B-cell lymphomas are the most common types of NHLs. Despite the considerable research progress on lymphomas, as well as the improved treatment regimens, the survival statistics remain poor, especially for the aggressive forms of NHLs. Currently, combination therapy is the preferred treatment modality for lymphoma, albeit with significant adverse side effects, particularly for the more aggressive types, such as Burkitt's lymphoma (BL) and mantle cell lymphoma (MCL). The majority of patients with BL respond poorly to the CHOP treatment (2). Similarly, many patients with MCL have a poor response to $\mathrm{CHOP}$, have high rates of relapse, with a median survival rate of 3-5 years (3). Finding drugs that specifically target BL and MCL while sparing normal cells is a major focus of current research. Because treatment failure depends on a complex interplay of factors including tumor biology, pharmacokinetics and pharmacogenomics $(4,5)$, the use of natural products, such as Huachansu (HCS), comprising many bioactive components (6) may prove to be more efficacious than a single agent or single agent combinations.

In traditional Chinese medicine (TCM), the use of Chansu was initially recorded in the Tang Dynasty, $>1,000$ years ago. Described in the Chinese pharmacopoeia as a detoxicant and an anodyne, its pharmacological attributes include detoxification and resuscitation as well as the ability to reduce swelling and pain associated with infections and malignant cell growth. Its wide use as a local anesthetic, a cardiotonic, and a diuretic has also been recorded. More recently, studies have suggested that Chansu inhibits vasodilation (increased vasoconstriction) and increases vascular resistance and blood pressure via its inherent anti-inflammatory effects and through inhibition of $\mathrm{Na}^{+}, \mathrm{K}^{+}$-ATPase (7). In addition, formulations of Chansu have been used for the treatment of various cancers including 
hepatic, pancreatic, gastric, lung, skin, and esophageal cancers in oncology clinics in China (8-10). Among the different formulations, Huachansu, an injectable form of Chansu, is one of the most popular formulations and has been extensively used in the treatment of various solid tumors including hepatocellular and non-small cell lung cancer in China (11).

As a form of traditional Chinese medicine approved by the State of Food and Drug Administration (SFDA), HCS and its bioactive components, cardiac glycosides (mainly bufadienolides), exhibited significant inhibitory activity against various human cancer cells, such as human colon cancer cells 26-L5; leukemia cells (K562, U937 and HL-60); hepatocellular carcinoma SMMC-7721, Bel-7402 and HepG2 cells; prostate cancer LNCaP, PC3 and DU145 cells; endometrial (HHUA and HEC-1), and ovarian (SK-OV-3) cancer cells (12-14). Mechanistically, the antiproliferative effect of HCS in the various cancer cells was mediated through cell cycle alteration and induction of apoptosis by modulating apoptosis-related proteins such as Bax, Bcl-2, Fas, Fas-L, survivin, and mitochondria-mediated pathways (15-18), as well as angiogenesis by inhibiting expression of VEGF and EGFR proteins $(19,20)$. Taken together, these studies support the notion that HCS and bufadienolides have the ability to suppress the proliferation of various solid tumors and, possibly, have great potential as anticancer agents. However, the effect of HCS on the growth of malignancies of hematopoietic origin, particularly lymphomas is limited. Case reports from China have demonstrated that HCS alone or in combination with $\mathrm{CHOP}$ enhances the response rate of patients with NHLs $(21,22)$ supporting its role in the management of NHLs.

In the present study, we investigated the potential antitumor activity and the associated molecular mechanisms of HCS in NHL cells. The antiproliferative effect of HCS and its fraction was evaluated on a number of different NHL cell lines including human Burkitt's B-cell lymphoma, such as Raji, Ramos, Namalwa and mantle cell lymphoma, SP53 cells. A transcriptome analysis of Ramos cells treated with HCS revealed HCS altered several interesting oncogenes, including MAP kinase. Given that a number of studies have demonstrated that pharmacologically targeting MAPK and inhibiting its activity decrease proliferation in a variety of tumor types (23), including NHL, HCS may have great potential to be developed as a targeted anticancer agent for NHL, particularly B-cell lymphomas.

\section{Materials and methods}

Chemical, reagents and antibodies. Huachansu was manufactured by Anhui JinChan Biochemistry Sharing Inc. (Anhui, China). DMSO was purchased from Sigma (St. Louis, MO, USA). ZDEVD was purchased from BD Pharmingen (Franklin Lakes, NJ, USA). ZDEVD was dissolved in DMSO and stored at $-20^{\circ} \mathrm{C}$. In all cases, the final concentration of DMSO was $<0.1 \%$ (vol/vol). PrestoBlue reagent was purchased from Invitrogen (Frederick, MD, USA). Caspase-3 (E8, sc-7272), caspase-9 (F-7, sc-17784), survivin (D-8, sc-17779), p21 (sc-187), Mcl-1 (sc-12756) were purchased from Santa Cruz (Santa Cruz, CA, USA); anti-cdk2 (BD-610145) and anti-cdk4 (BD-610147) were purchased from BD Transduction Laboratories (Franklin Lakes, NJ, USA); Rb (4H1, CS-9309), phospho-Rb (ser308)
(CS-2181), p38MAPK (CS-9212S) were purchased from Cell Signaling (Danvers, MA, USA), pMAPK (V803A) was purchased from Promega (Madison, WI, USA) and $\beta$-actin (S-A5441) was purchased from Sigma; RNase A was purchased from Invitrogen (Carlsbad, CA, USA); Propidium iodide was purchased from BD Pharmingen (San Diego, CA, USA).

Fractionation of HCS. To obtain the water and lipid soluble fractions, HCS was subjected to a solid phase extraction using Sep-Pak C18 Cartridge (Waters Corp., Milford, MA, USA). Briefly, an aliquot of HCS $(1 \mathrm{ml})$ was applied to a preconditioned Sep-Pak solid phase extraction cartridge $(1 \mathrm{ml} / 50 \mathrm{mg}$, Waters Corp.). The eluate was collected and defined as water soluble fraction. The column was then washed with $1 \mathrm{ml}$ of water and lipid soluble compounds were eluted with $1 \mathrm{ml}$ of ethyl acetate, after which the effluent was collected (lipid soluble fraction). The water-soluble fraction was used as is and the lipid fraction was dried down in a stream of liquid nitrogen and reconstituted to an equivalent volume of DMSO $(1 \mathrm{ml})$ as that of the water soluble fraction.

Cell culture. Human Burkitt's B-cell lymphoma cells, Raji, Ramos and Namalwa cells were purchased from American Tissue and Culture Collection (ATCC, Manassas, VA, USA). Mantle cell lymphoma cell line, SP53, was kindly provided by Dr James You at The University of Texas MD Anderson Cancer Center. All cells were cultured in RPMI-1640 medium supplemented with $10 \%$ fetal bovine serum (FBS; Hyclone, Logan, UT, USA), $1 \mathrm{mM}$ L-glutamine, and $50 \mathrm{IU} / \mathrm{ml}$ penicillin and $50 \mu \mathrm{g} /$ $\mathrm{ml}$ streptomycin. Human peripheral blood mononuclear cells (PBMCs) were purchased from Astarte Biologics (Redmond, WA, USA) and cultured in RPMI-1640 medium. Cells were cultured at $37^{\circ} \mathrm{C}$ with $5 \% \mathrm{CO}_{2}$ in a humid atmosphere.

Cell viability and proliferation. The effect of HCS or bufalin on the growth of lymphoma cells was assessed by the PrestoBlue assay. Raji, Ramos, Namalwa and SP53 cells were seeded at a density of $1 \times 10^{4}$ cells per well in 96-well plates in RPMI medium and incubated for $24 \mathrm{~h}$. Following incubation, media was replaced and the cells were treated with the indicated concentrations of HCS $(0.195-50 \mu \mathrm{l} / \mathrm{ml})$ or different fraction of HCS, i.e., the water or lipid soluble fractions, or bufalin $(1.95-1,000 \mathrm{nM})$ for $72 \mathrm{~h}$. The cell viability was then measured using the PrestoBlue reagent according to the manufacturer's instructions. Briefly, $20 \mu \mathrm{l}$ of the PrestoBlue reagent was added to each well containing $200 \mu \mathrm{l}$ media. After $1 \mathrm{~h}$ of incubation at $37^{\circ} \mathrm{C}$, the absorbance was read at a wavelength of $590 \mathrm{~nm}$ (Ex/Em, 560/590 nm) using a V-Max Micro-plate Reader by Molecular Devices, Inc. (Sunnyvale, CA, USA). Experiments were repeated at least three times.

Cell cycle, apoptosis and cell-death. For cell cycle analysis, Ramos cells $\left(2.5 \times 10^{6}\right)$ grown in $100-\mathrm{mm}$ dishes were treated with HCS (5 and $25 \mu \mathrm{l} / \mathrm{ml}$ ) or bufalin (10 and $50 \mathrm{nM}$ ) for $24 \mathrm{~h}$. Cells were centrifuged, the pellets were resuspended and washed in $1 \mathrm{X}$ PBS, and fixed overnight in $70 \%$ ethanol at $4^{\circ} \mathrm{C}$. They were then washed with $1 \mathrm{X}$ PBS and resuspended in staining solution (PBTB) containing PBS, 0.5\% BSA, $0.005 \%$ Tween-20, $10 \mu \mathrm{g} / \mathrm{ml}$ propidium iodide (PI) and $1 \mu \mathrm{g} / \mathrm{ml}$ of DNase-free RNase. Cells were incubated in the dark for 
$30 \mathrm{~min}$ at $37^{\circ} \mathrm{C}$ prior to analysis by fluorescence-activated cellsorting analysis (FACS) using a FACSCalibur flow cytometer (Becton-Dickinson). The percentage of cells in each phase of the cell cycle was estimated from the DNA histogram content. Apoptotic cell death was further measured by Annexin V surface staining. Briefly, cells $\left(2.5 \times 10^{6}\right)$ were double stained with fluorescein isothiocyanate (FITC) conjugated Annexin V and PI according to the manufacturer's instructions (BD Biosciences, San Diego, CA, USA). Fluorescence was detected by the FACSCalibur flow cytometer and analyzed using CellQuest software program (Becton-Dickinson). To determine the effect of caspase-3 inhibitor on HCS induced apoptosis, cells were treated with HCS in the presence or absence of the caspase-3 inhibitor, benzyloxycarbonyl-AspGlu-Val-Asp-fluoromethylketone (ZDEVD-fmk) $(20 \mu \mathrm{M})$ followed by Annexin V staining. For DNA laddering, the DNA was extracted, resolved on a $1 \%$ agarose gel, photographed using the Chemidoc-Transilluminator XRS instrument (Bio-Rad, Hercules, CA, USA) and the image captured using the Quantity One software system.

Immunoblotting. Cytosolic extracts were prepared from Ramos cells treated with HCS with and without ZDEVD as well as bufalin (10 and $50 \mathrm{nM}$ ) for $24 \mathrm{~h}$. Briefly, cells were washed in PBS and then resuspended in $50 \mu 1$ of lysis buffer $20 \mathrm{mM}$ HEPES ( $N$-2-hydroxyethylpiperazine- $N$ '-2ethanesulfonic acid), $\mathrm{pH} 7.5,10 \mathrm{mM} \mathrm{KCl}, 1.5 \mathrm{mM} \mathrm{MgCl}_{2}$, $1 \mathrm{mM}$ EDTA (ethylenediaminetetraacetic acid), and $1 \mathrm{mM}$ dithiothreitol (DTT)]. After sonication on ice for 3 min with a sonicator 3000 (Misonex Inc., Farmingdale, NY, USA), the protein concentrations were determined by the Bradford assay. Immunoblot assays were performed as per standard procedure. Briefly, equal amounts (50 $\mu \mathrm{g})$ of protein were subjected to sodium dodecyl sulfate-polyacrylamide gel electrophoresis (SDS-PAGE) followed by transfer to PVDF membranes. Membranes were probed with the indicated antibodies. Secondary antibodies consisting of horseradish peroxidase (HRP)-conjugated goat anti-mouse IgG and anti-rabbit IgG $(1: 500 \mathrm{vol} / \mathrm{vol})$ were purchased from Santa Cruz. Detection was performed by the enhanced chemiluminescence method from GE Healthcare (Little Chalfont, Buckinghamshire, UK).

Transmission electron microscopy. Ramos cells $\left(5 \times 10^{6}\right)$ were seeded in 100-mm dishes. The cells were then incubated at $37^{\circ} \mathrm{C}, 5 \% \mathrm{CO}_{2}$ for $\sim 12-24 \mathrm{~h}$. Following treatment with $\mathrm{HCS}$ $(0,25 \mu \mathrm{l} / \mathrm{ml})$ for $24 \mathrm{~h}$, the cells were harvested by centrifugation at 3,000 rpm for $2 \mathrm{~min}$. After two washes with $1 \mathrm{X}$ PBS, the pellet was resuspended in fixative (2\% paraformaldehyde and $3 \%$ gluteraldehyde) and stored at $4{ }^{\circ} \mathrm{C}$. Samples were fixed with a solution containing $3 \%$ glutaraldehyde plus $2 \%$ paraformaldehyde in $0.1 \mathrm{M}$ cacodylate buffer, $\mathrm{pH} 7.3$, for $1 \mathrm{~h}$. After fixation, the samples were washed and treated with $0.1 \%$ Millipore-filtered cacodylate buffered tannic acid, postfixed with $1 \%$ buffered osmium tetroxide for $30 \mathrm{~min}$, and stained en bloc with $1 \%$ Millipore-filtered uranyl acetate. The samples were dehydrated in increasing concentrations of ethanol, infiltrated, and embedded in LX-112 medium. The samples were polymerized in a $60^{\circ} \mathrm{C}$ oven for 2 days. Ultrathin sections were cut in a Leica Ultracut microtome (Leica, Deerfield, IL, USA), stained with uranyl acetate and lead citrate in a Leica EM
Stainer, and examined in a JEM 1010 transmission electron microscope (Jeol, USA, Inc., Peabody, MA, USA) at an accelerating voltage of $80 \mathrm{kV}$. Digital images were obtained using AMT Imaging System (Advanced Microscopy Techniques Corp., Danvers, MA, USA).

Gene expression. Ramos cells $\left(2.5 \times 10^{6}\right)$ were seeded overnight in $100-\mathrm{mm}$ dishes and were then treated with $25 \mu \mathrm{l} / \mathrm{ml}$ of HCS for $24 \mathrm{~h}$. Total RNA was extracted using an RNeasy kit (Qiagen, Valencia, CA, USA). Gene expression analysis was performed at the The University of Texas MD Anderson Sequence and Microarray Core facility, using the Affymetrix Gene chip 1.0 ST. Gene expression analysis was normalized by $\beta$-actin expression and set to 1 for the control DMSO-treated cells.

Statistical analysis. Student's t-test was used to determine the statistical differences between various experimental groups; a value of $\mathrm{P} \leq 0.05$ was considered statistically significant.

\section{Results}

HCS and its lipid fraction inhibit proliferation of lymphoma cell lines but not human PBMCs. To investigate the effects of HCS on cell proliferation in lymphomas, we treated three human Burkitt's non-Hodgkin's lymphoma cell lines, Raji, Ramos and Namalwa as well as mantle cell lymphoma SP53 cells with various concentrations of HCS. HCS markedly inhibited cell proliferation in all three cell lines tested in a doseand time-dependent manner, with $\mathrm{IC}_{50}$ of inhibition ranging from $3.125 \mu \mathrm{l} / \mathrm{ml}$ for Ramos and Namalwa to $25 \mu \mathrm{l} / \mathrm{ml}$ for Raji cells (Fig. 1A). A comparable level of antiproliferative effect, $\mathrm{IC}_{50}$ of $\sim 1.5 \mu \mathrm{l} / \mathrm{ml}$, was achieved when mantle cell lymphoma SP53 cells were treated with HCS (Fig. 1A). In contrast to the lymphoma cells, HCS did not affect the proliferation of human PBMC (Fig. 1A). Because a number of bioactive components either water or lipid soluble are present in HCS, we tested for antiproliferation of the aqueous and lipid fractions in the Ramos cells. In Fig. 1B, the lipid fraction exhibited antiproliferative activity comparable to the parent HCS whereas the aqueous fraction showed no antiproliferative activity in these cells, suggesting that the lipid fraction is responsible for the antiproliferative effect in HCS.

Effects of HCS on the cell cycle and cell death in Ramos cells. We next investigated the type of cell death elicited by HCS in Ramos cells, which is most sensitive to HCS treatment. After treatment with increasing concentrations $(0,5$ and $25 \mu \mathrm{l} / \mathrm{ml}$ ) of HCS for $24 \mathrm{~h}$, cells were subjected by Annexin V/ propidium iodide (PI) staining followed by flow cytometry analysis. HCS treatment resulted in a dose-dependent increase in sub-G1 phase arrest (Fig. 2A-b and -c) compared to vehicle treated cells (Fig. 2A-a). Compared to control cells, there was a $\sim 10$-fold increase in sub-G1 phase cells in HCS $(25 \mu 1 /$ $\mathrm{ml}$ ) treated samples, suggesting the induction of apoptosis (Fig. 2A-d). The induction of apoptosis by HCS in Ramos cells was further evidenced by increased both early and late apoptotic cell population with Annexin V- and PI staining, in a dose-dependent manner (Fig. 2B-b and c) compared to control cells (Fig. 2B-a). In fact, HCS $25 \mu \mathrm{l} / \mathrm{ml}$ increased late 

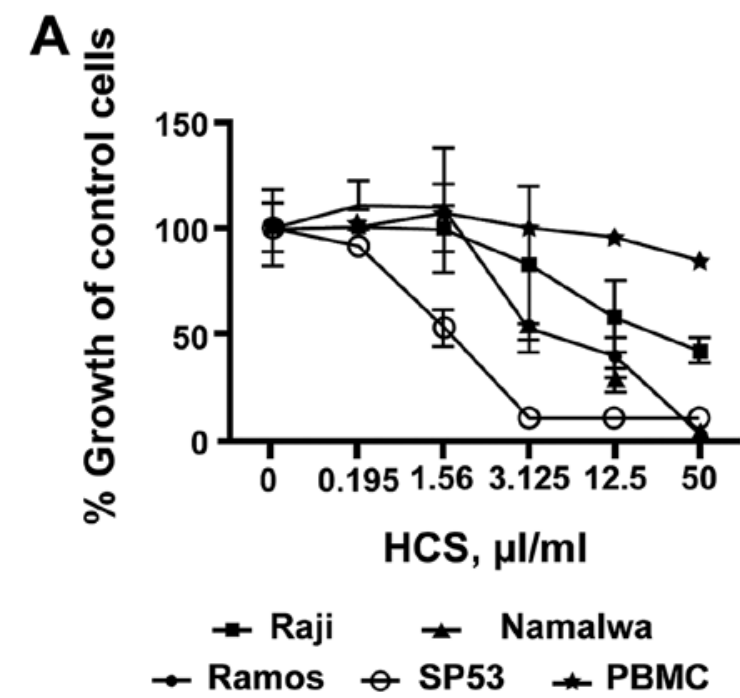
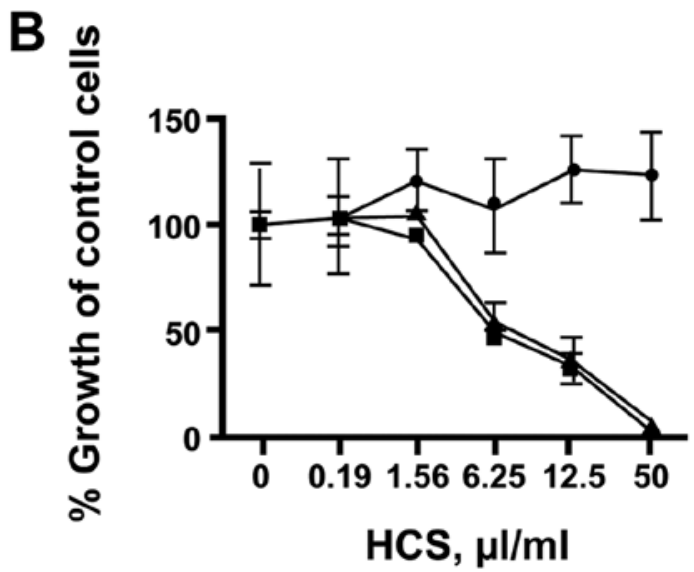

$\rightarrow$ Water fraction $\rightarrow$ HCS $\neq$ Lipid fraction

Figure 1. Huachansu (HCS) inhibits cell proliferation of human non-Hogdkins lymphoma cells. (A) Burkitt's lymphoma cells Raji, Ramos, Namalwa, mantle cell lymphoma (SP53), and normal PBMC cells were treated with HCS $(0.02-50 \mu 1 / \mathrm{ml})$ for $72 \mathrm{~h}$. (B) Ramos cells were treated for $72 \mathrm{~h}$ with HCS, water and lipid fraction at the indicated concentrations. Cell proliferation was evaluated by the PrestoBlue assay. Each experiment was performed in quadruplicate and repeated at least twice independently. Data are presented as mean \pm SD.
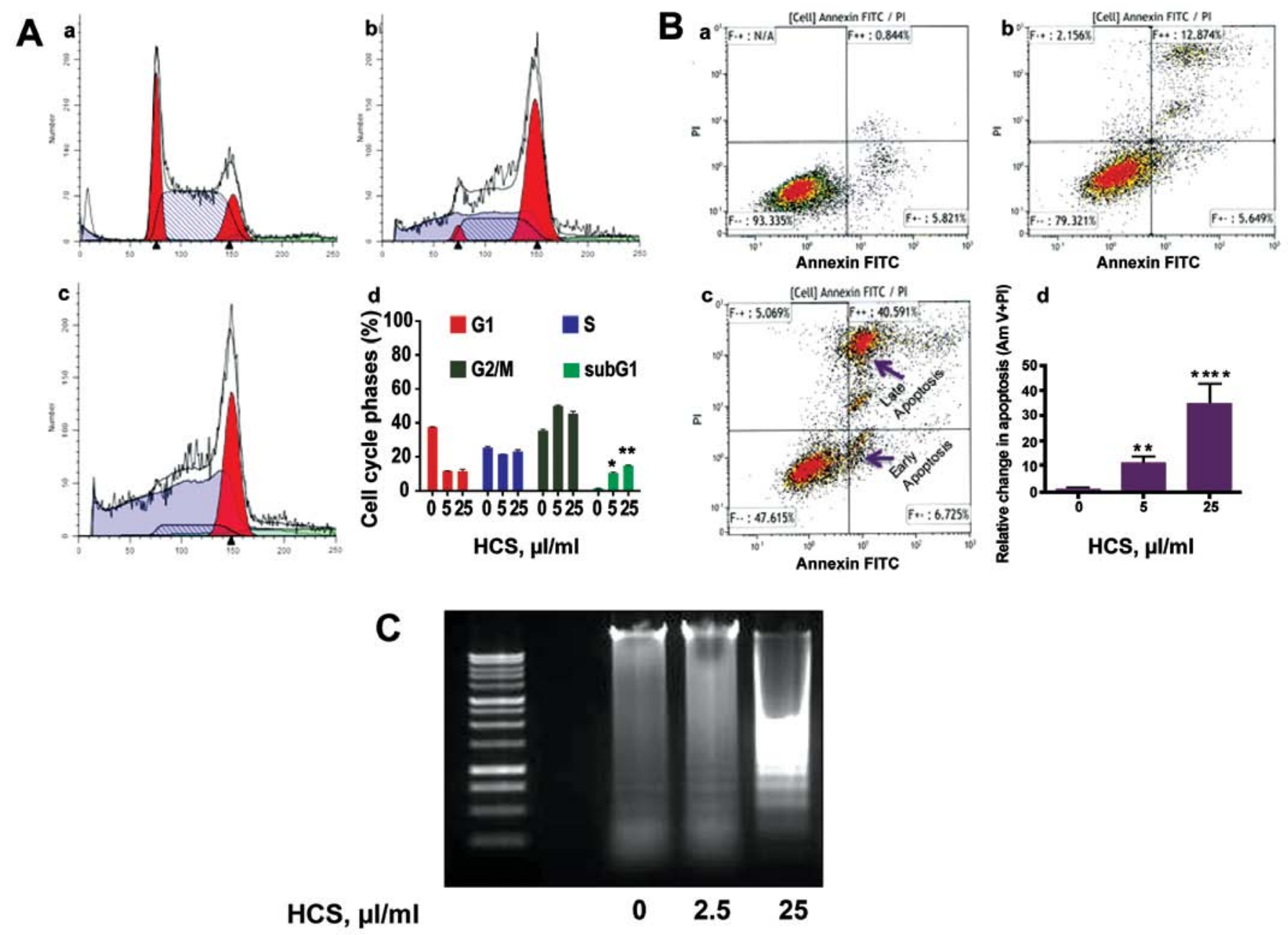

Figure 2. HCS triggers cell arrest and induces cell death of Ramos cells. Cells were treated with HCS for 24 h. (A) Histograms of Ramos cells treated with vehicle (a), HCS $5 \mu 1 / \mathrm{ml}$ (b) and HCS $25 \mu 1 / \mathrm{ml}$ (c) and quantitative analysis of the cell cycle alteration elicited by HCS (d). (B) Cells were treated with HCS at similar concentrations illustrated in sub-figure A, and apoptotic cells were assayed by flow cytometry following Annexin V staining, using a FACSCalibur instrument. Each experiment was performed in duplicate and repeated twice independently. Each bar graph represents the mean and the error bars represent \pm SEM. ${ }^{*} \mathrm{P}<0.05,{ }^{* * *} \mathrm{P}<0.01,{ }^{* * * * *} \mathrm{P}<0.001$ statistically significant difference between HCS treated versus vehicle treated cells. (C) Ramos cells were treated with HCS at 2.5 and $25 \mu 1 / \mathrm{ml}$ for $24 \mathrm{~h}$. The DNA was extracted, resolved on a $1 \%$ agarose gel, stained with ethidium bromide and photographed. 

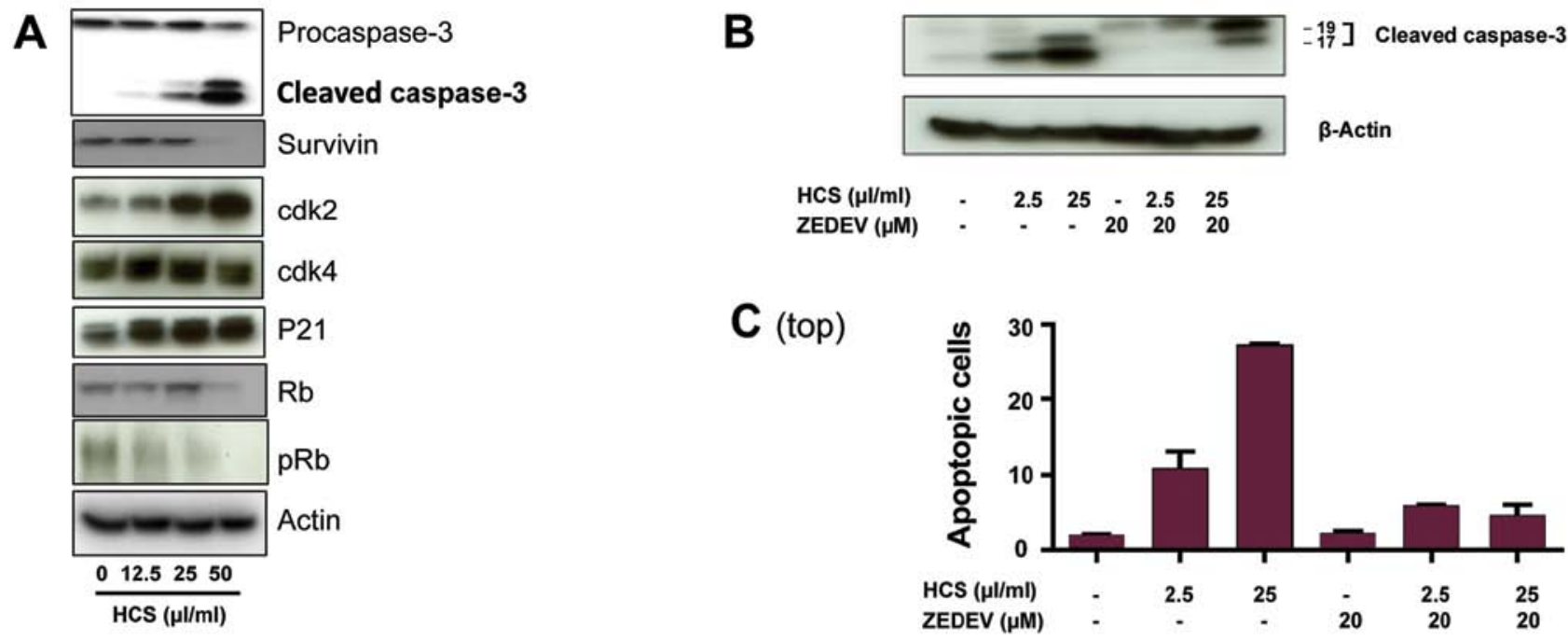

C (bottom)
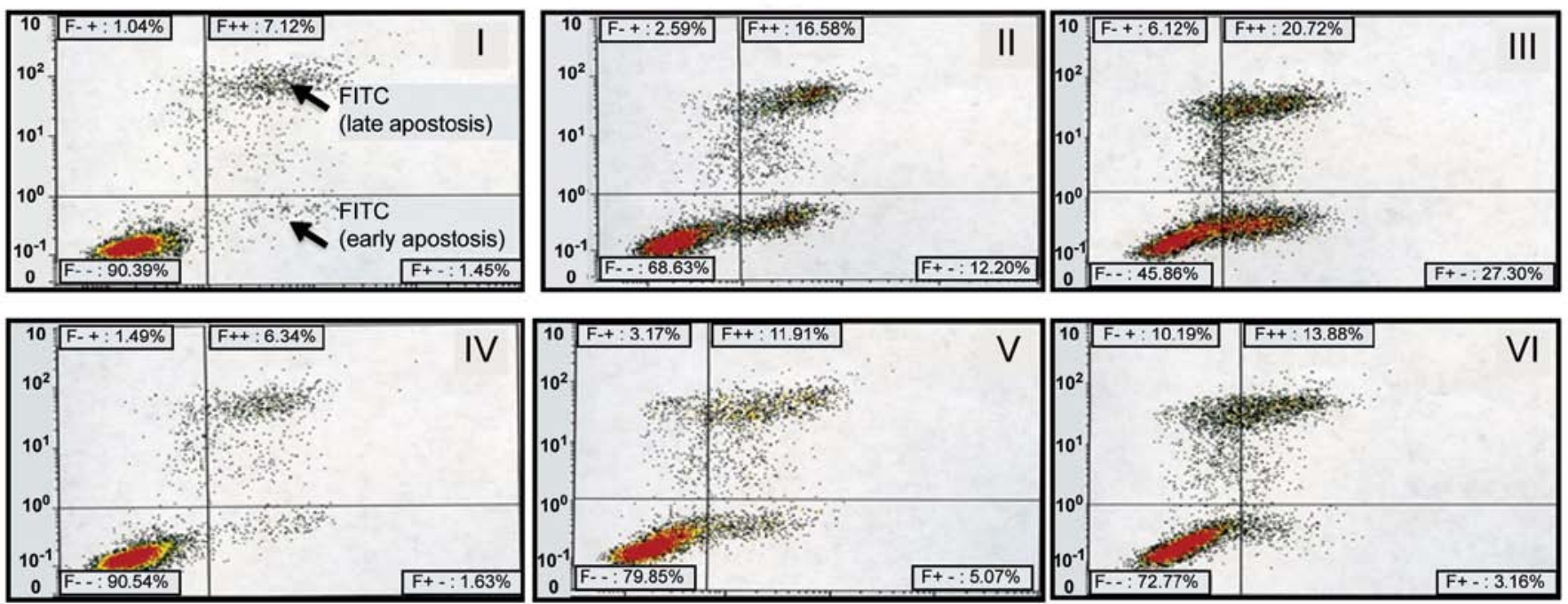

Figure 3. Modulation of apoptotic and cell cycle regulatory proteins in Ramos cells treated with HCS. (A) Ramos cells were treated with HCS $(0,12.5,25$ and $50 \mu \mathrm{l} / \mathrm{ml}$ ) for $24 \mathrm{~h}$, followed by western blot analysis to detect caspase-3, cdk2, cdk4, p21 $1^{\mathrm{CIP} 1}$, survivin, Rb and pRb proteins. (B) Cells were treated with the indicated concentrations of HCS with or without the caspase inhibitor, ZDEVD, for $24 \mathrm{~h}$ and immunoblotted with the caspase-3 antibodies. (C) The effect of ZDEVD on HCS induced apoptotic cell death by Annexin V staining. ZDEVD markedly blocked the early phase of apoptosis induced by HCS while moderately modulated the late phase of apoptotic or necrotic cells (top, bar graph of early phase apoptosis; bottom, histogram). Each experiment was performed in duplicate and repeated twice independently. Data are presented as mean \pm SD.

stage apoptosis by almost 35 -fold compared to vehicle treated cells (Fig. 2B-d). The formation of internucleosomal DNA fragments is frequently used as a marker for cells undergoing programmed cell death. Fig. 2C is indicative of the DNA laddering pattern triggered, in a dose-dependent manner, by HCS treatment.

HCS modulates key regulatory proteins critical for cell growth in lymphoma cells. We next investigated how cell cycle and apoptotic cell death regulatory proteins were impacted by HCS. Immunoblotting analyses showed an increase of the cyclin-dependent kinase inhibitor $\mathrm{p} 21^{\mathrm{CIP} 1}$, a key regulator of the cell cycle, at a low concentration of $12.5 \mu \mathrm{l} / \mathrm{ml}$. In contrast, there was a dose-dependent decrease in phosphorylated $\mathrm{Rb}$ (pRb) protein and survivin (Fig. 3A). Additionally, HCS resulted in a dose-dependent increase of caspase-3, as this caspase is cleaved from the procaspase to an active caspase when cells undergo caspase-dependent apoptotic cell death. To further confirm the role of caspase-3 in HCS-induced cell death, Ramos cells were treated with HCS and the caspase-3 specific inhibitor ZDEVD-FMK for $24 \mathrm{~h}$, followed by detection of active caspase- 3 by western blot analysis. Fig. $3 \mathrm{~B}$ shows that HCS alone induced formation of active caspase-3, in a dosedependent manner, whereas ZDEVD alone inhibited active caspase- 3 formation. The combination of HCS and ZDEVD abrogated the HCS effect alone, as evidenced by the marked decrease in the 17-kDa fragment of caspase-3 in the ZDEVD. In line with this, the results of Annexin $\mathrm{V}$ staining of Ramos cells treated with ZDEVD alone and in combination with HCS mirrored the active caspase-3 cell death depicted in Fig. 3B, as the combination of ZDEVD and HCS significantly reduced the cells undergoing the early phase apoptosis and partially abrogated late phase apoptotic cell death (Fig. 3C, V and VI) compared to that caused by HCS alone (Fig. 3C, II and III), 

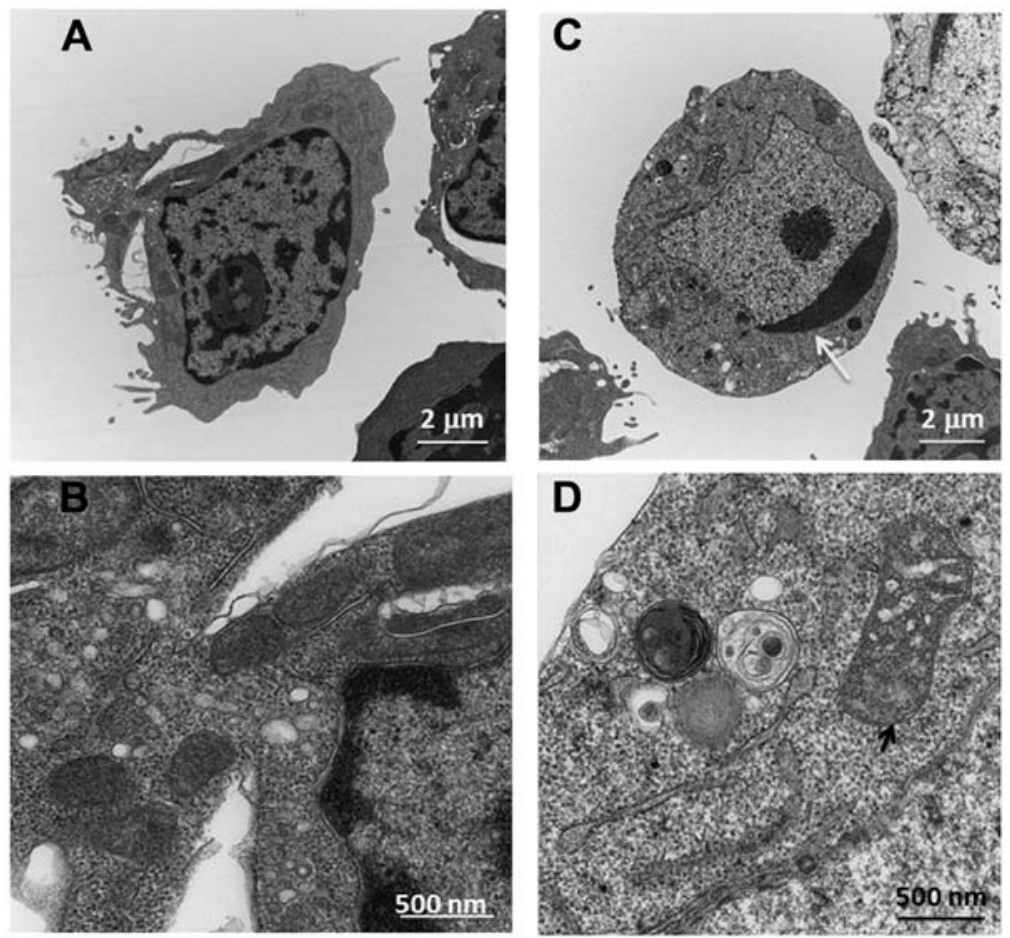

Figure 4. Ultrastructure of Ramos cells treated with HCS by transmission electron microscopy. Ramos cells were treated with $\mathrm{HCS}(0$ and $25 \mu \mathrm{l} / \mathrm{ml})$ for $24 \mathrm{~h}$. Following treatment, cells were harvested and processed for TEM, as described in Materials and methods. (A) Control Ramos cells (x5,000). (B) Control Ramos cells (x10,000); (C) HSC (25 $\mu 1 / \mathrm{ml})$ treated Ramos cells (x5,000); (D) HSC (25 $\mu 1 / \mathrm{ml})$ treated Ramos cells (x10,000). The white arrow indicates condensed chromosome in HCS treated Ramos cells, while the black arrow points to enlarged and swollen mitochondria in the HCS treated Ramos cells.

whereas ZDEVD alone did not affect cell death (Fig. 3C, IV) compared to that of control group (Fig. 3C, I).

Ultrastructural changes of Ramos cells by transmission electron microscopy. To further confirm that HCS mediated cell death through apoptosis in Ramos cells, we determined the ultrastructural changes of Ramos cells after being treated with HCS using transmission electron microscopy (TEM). As shown in Fig. 4, HCS $(25 \mu \mathrm{l} / \mathrm{ml})$ induced marked ultrastructural changes in cellular organelles, especially condensed chromatin in the nucleus and distorted mitochondria (see arrows in Fig. 4C and D) compared to that of control treated cells (Fig. 4A and B), further suggesting that the antiproliferative effect of HCS is being mediated through the induction of apoptosis.

HCS affects MAP kinase gene and protein expression. To determine the molecular mechanisms associated with HCS-induced cell death on Ramos cells at the transcriptional level, we treated Ramos cells with $25 \mu \mathrm{l} / \mathrm{ml}$ of HCS for $24 \mathrm{~h}$ and the alteration of gene expression was assessed using an Affymetrix chip. All genes showing 10-40-fold up- or downregulation are summarized in Fig. 5A. Among these highly regulated genes, the mRNA expression of MAP2K6 was reduced by 19 -fold compared to that of vehicle treated Ramos cells. To gain further insights into whether HCS also regulated the MPA kinase translationally, we treated Ramos cells with $\mathrm{HCS}$ for $24 \mathrm{~h}$ and determined the protein expression of MAP kinase by immunoblotting. As shown in Fig. 5B, expression of phosphorylated MAPK and ERK was suppressed in a concentration-dependent manner, with no changes in the total

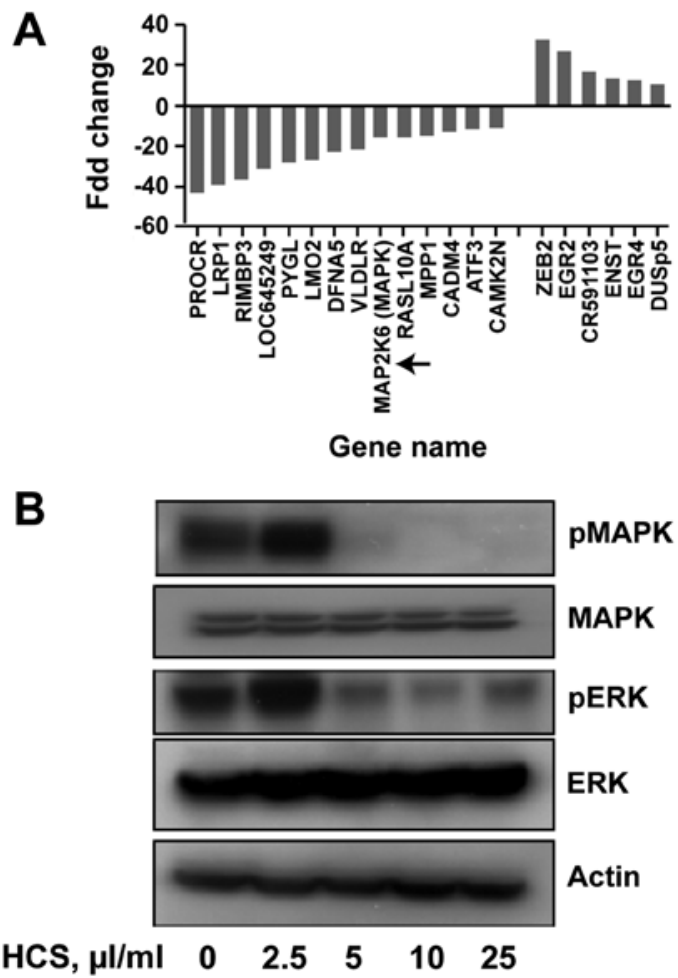

Figure 5. Gene expression analysis and assessment of signaling pathways perturbed by HCS in Ramos cells. Cells were treated with $25 \mu 1 / \mathrm{ml}$ of HCS for $24 \mathrm{~h}$ and gene expression analysis was performed at the MD Anderson microarray core facility, using an Affymetrix chip. (A) Genes were up- and downregulated $~ 10-40$-fold in HCS treated Ramos cells relative to vehicle treated cells. (B) The expression of MAP kinase pathway proteins in Ramos cells treated with HCS at the indicated concentrations for $24 \mathrm{~h}$. Cell lysates were then subjected to western blot analysis for total and phosphorylated levels of MAPK and ERK proteins. 

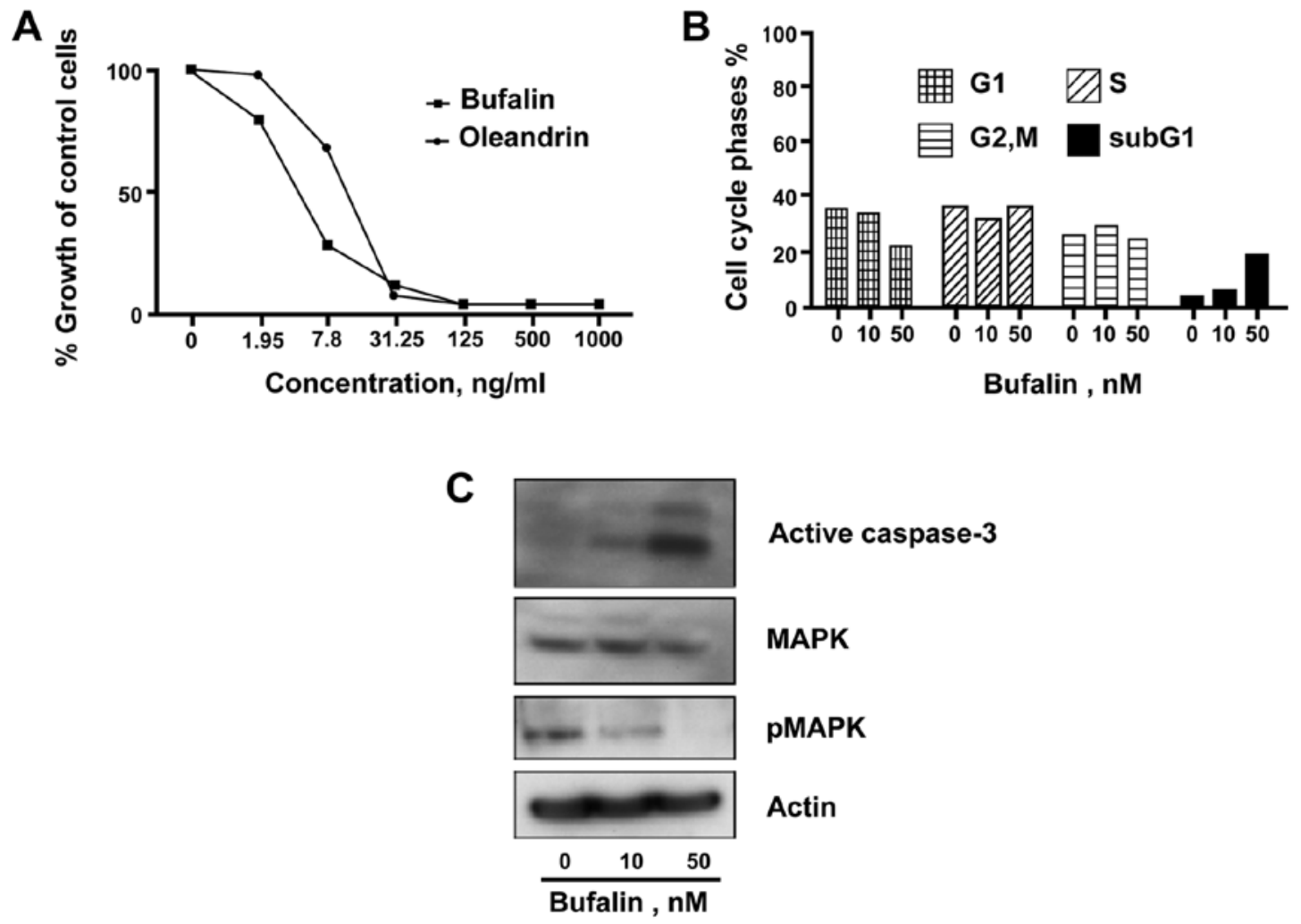

Figure 6. Effects of bufalin on proliferation, cell cycle and cell signaling proteins in Ramos cells. (A) The effect of bufalin and oleandrin in the growth of Ramos cells that were treated with these particular agents for $72 \mathrm{~h}$. Proliferation assay using the PrestoBlue reagent was performed as described in Materials and methods. The unit of conversion for bufalin is $10 \mathrm{ng} / \mathrm{ml}=26 \mathrm{nM}$ and for oleandrin, $10 \mathrm{ng} / \mathrm{ml}=17 \mathrm{nM}$. (B) Cell cycle and apoptotic cell death in Ramos cells treated with bufalin (10 and $50 \mathrm{nM}$ ) for $24 \mathrm{~h}$. (C) The expression of active caspase-3 and MAP kinase in Ramos cells treated with bufalin for $24 \mathrm{~h}$.

MAPK and ERK, potentially implicating HCS in the inhibition of the MAP kinase signaling pathway. Together, these findings suggest that, in addition to the caspase-3-mediated cell death, HCS might also induce cell death in lymphomas through inhibition of MAP kinase signaling.

Cardiac glycosides, the major component of HCS, inhibited Ramos cells by induction of apoptosis. Bufalin, the major cardiac glycoside present in HCS, has been shown to have relatively potent anticancer activity in various solid tumors (24). To test its antiproliferative effect in NHL, we treated Ramos cells with bufalin and another cardiac glycoside, oleandrin, for 24 and $72 \mathrm{~h}$ and assayed for cell cycle and proliferation, respectively. The proliferation analysis showed a marked growth inhibition of Ramos cells with an $\mathrm{IC}_{50}$ of $5 \pm 0.15 \mathrm{ng} / \mathrm{ml}$ and $15 \pm 0.18 \mathrm{ng} / \mathrm{ml}$ for bufalin and oleandrin, respectively (Fig. 6A). The cell cycle analysis showed a dose-dependent increase in the sub-G1 cell population, following treatment of Ramos cells with bufalin at a relatively low concentration of $50 \mathrm{nM}$ (Fig. 6B). Similar to the effect of HCS, bufalin treatment of Ramos cells increased formation of activated caspase- 3 as well as decreased pMAPK levels (Fig. 6C).

\section{Discussion}

Nature abounds with drugs that are exploited by humans for the treatment of a variety of ailments $(25,26)$. Many anticancer agents are derived from natural sources, primarily from plants (27). Animal-derived anticancer drugs are also available, including ARA-C, modeled after compounds from the Caribbean sponge, used to treat leukemia and lymphoma (28). The drug TM 601 is derived from the Israeli yellow scorpion and attacks malignant glioma tumors, without harming healthy cells (29). ET 743, which comes from sea squirts, is being tested for treatment of ovarian cancer and soft tissue sarcoma (30-32). A number of marine natural products and related compounds have progressed on to clinical trials (33). Herein, we report that HCS inhibited cell proliferation, and induced cell death through apoptosis in human NHL cells.

In these investigations, we found that HCS, at clinically achievable doses, significantly inhibited the proliferation of a number of NHL cells, especially Ramos. The antiproliferative effect of HCS in NHL appears to be mediated through induction of apoptosis of Ramos cells via activation of caspase-3 pathway. Intriguingly, HCS also downregulated the MAP kinase translationally and transcriptionally in Ramos cells. Given that the MAP kinase pathway has been recognized as one of the most important oncogenic pathways in aggressive B-cell lymphoma $(34,35)$, HCS certainly warrants further investigation.

As a hot water extract of toad skin, HCS contains multiple biologically active components. To ascertain the most active components that are responsible for HCS-mediated anticancer activity, we separated HCS into lipid- or water-soluble components using reverse phase solid phase extraction method. As depicted in Fig. 1B, the lipid component inhibited proliferation comparable to the HCS mixture, whereas the water-soluble fraction had no measurable effect. These results indicated 


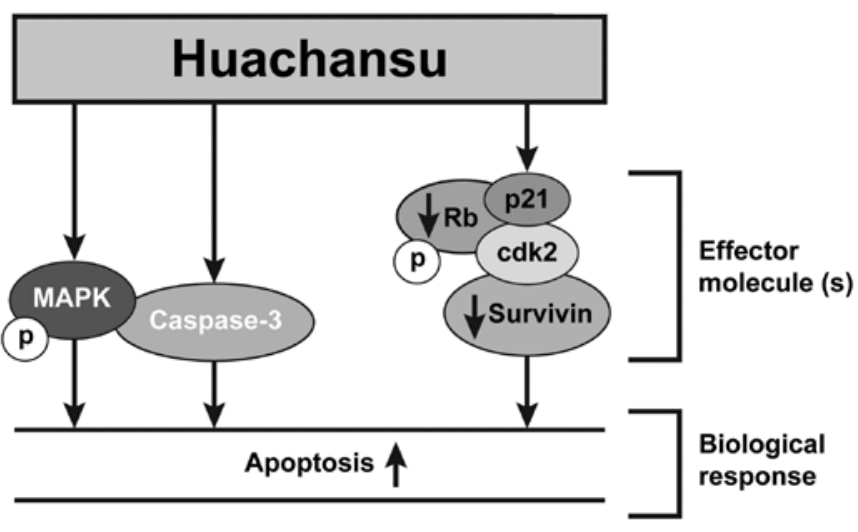

Figure 7. Proposed signaling pathway modulation in lymphomas by HCS.

that the lipid-fraction of HCS is primarily responsible for its antiproliferative activity. We, and others, have reported that cardiac glycosides (bufadeinolides), especially, bufalin, the major bioactive component of HCS are responsible for HCS-mediated anticancer activity in various solid tumors (36). However, whether bufalin is also capable of inhibiting the proliferation of NHL, particular Burkitt's B-cell lymphoma, is lacking. In this study, our results showed that, at as low as $5 \mathrm{ng} / \mathrm{ml}$, bufalin inhibited proliferation of Ramos cells by $50 \%$ suggesting that it has potent anticancer effect in NHL cells. Additionally, bufalin inhibited proliferation of Ramos cells through induction of apoptosis, activation of the caspase-3 pathways, and inhibition of the MAP kinase pathway (Fig. 7, model), suggesting that bufalin could be a main bioactive component responsible for HCS anticancer activity in aggressive B-cell lymphomas.

The proapoptotic effect of HCS or its bioactive components, such as cardiac glycosides, has been reported in solid tumor derived cell lines, such as hepatocellular carcinoma HepG2 cells, and proposed to act mainly through downregulation of mitochondria- and Fas-mediated caspase-dependent pathway (6). Active caspase-3 is a homodimer of heterodimers and is produced by proteolysis of procaspase-3 (37). Programmed cell death (apoptosis) can occur through caspase-dependent and -independent pathways (38). In light of the previous study, we reasoned that HCS might also directly activate procaspase-3 and cause induction of apoptosis in B-cell lymphoma cells. Indeed, when Ramos cells were treated with HCS with and without the caspase inhibitor, ZDEVD, a cell-permeable, irreversible inhibitor of caspase-3/CPP32 that is known to inhibit cell apoptosis, ZDEVD blocked formation of lower molecular forms of active caspase-3 induced by HCS. In line with this, ZDEVD also partially blocked the proapoptotic activity of HCS, suggesting the activation of caspase-3 could be in part attributable to HCS antiproliferative effect in Ramos cells. This is consistent with previous research with HCC cells (6). In HCC cell lines treated with HCS, the activation of caspase- 9 was also observed $(6,39)$. In contrast, the expression of caspase-9 in the HCS treated Ramos cells was not altered (data not shown), suggesting the HCS-induced apoptotic effect is mediated through different molecular mechanisms in $\mathrm{HCC}$ and B-cell lymphomas. More detailed biochemical in vitro assays in cell lines and in freshly isolated tumors as well as in vivo tumor regression analyses in animal models need to be conducted to gain a better idea of the mode of action of HCS.

In contrast to caspase-3 activation by HCS, MAP kinases gene and protein were downregulated in Ramos cells treated with HCS. MAPKs are widely expressed serine-threonine kinases that mediate important regulatory signals in the cell. Activation of MAPK pathway is a critical event for a number of solid tumors as well as NHL (40). For example, Green et al reported that the genetic alteration of the MAPK and apoptotic pathways alone or with genetic amplification of FOXM1 as a conserved mechanism of lyphomagenesis in NHL including FLs, DLBCLs and B-CLL (41). Three major MAP kinase pathways, designated by their terminal kinases, have been extensively studied: the extracellular signal-regulated kinase (ERK1/2), c-Jun N-terminal kinase (JNK1/2), and p38 kinase pathways. These MAP kinases are activated via a series of sequential phosphorylations of upstream kinases, and they function primarily to transduce signals to the cell nucleus, ultimately affecting gene expression. The role of bufalin on MAP kinase has been studied by a number of investigators suggesting that bufalin induces apoptosis by activation of MAPKK1 and JNK pathways in human leukemia U937 and HL-60 cells. In contrast, Jiang et al reported that bufalin inhibited the phosphorylation of Akt, NF-kB, p44/42 MAPK (ERK1/2), and p38 MAPK in A549 cells (42) suggesting MAP kinase could be differentially regulated by bufalin depending on tumor cell types.

The current study is the first to examine the effect of HCS on MAPK pathways in relation to its induced cell death in lymphomas, especially NHL. We showed that HSC at as low as $5 \mu \mathrm{l} / \mathrm{ml}$ blocked almost $90 \%$ phosphorylation of MAPK and 50\% phosphorylation of ERK while no changes were observed with total MAPK expression. Similarly, bufalin also decreased MAPK phosphorylation in a dose-dependent manner in Ramos cells. Taken together, our data suggest that HCS mediates cell death possibly through modulation of the MAP kinase pathway.

In conclusion, we reported that HCS can potently inhibit proliferation of NHL, especially Burkett's non-Hodgkin's lymphoma cells. The anticancer activity of HCS appears to be linked to the induction of apoptosis in non-Hodgkin's lymphomas by specific activation of caspase-3. Additionally, MAP kinases were also notably downregulated. This is the first study suggesting the anticancer potential of HCS in hematologic malignancies. Given that the result of our phase I study on HCS and solid tumors has suggested that HCS is well tolerated with minimum side effects at doses as high as $120 \mathrm{ml} /$ $\mathrm{m}^{2}$, which is almost 6 -fold higher than the dose $\left(20 \mathrm{ml} / \mathrm{m}^{2}\right)$ regularly used in oncology clinics in China, HCS, therefore, warrants further investigation as a novel treatment modality in NHL.

\section{Acknowledgements}

This study was supported in part by a grant from the Gabrielle's Angel Foundation. The TEM study was supported by the Institutional Core grant no. CA16672 high Resolution Electron Microscopy Facility, UTMDACC. P. Yang and L. Cohen serve as consultants for Anhui Jinchan Biochemistry Sharing Inc. 


\section{References}

1. Evans LS and Hancock BW: Non-Hodgkin lymphoma. Lancet 362: 139-146, 2003

2. Vose JM, Link BK, Grossbard ML, Czuczman M, GrilloLopez A, Gilman P, Lowe A, Kunkel LA and Fisher RI: Phase II study of rituximab in combination with chop chemotherapy in patients with previously untreated, aggressive non-Hodgkin's lymphoma. J Clin Oncol 19: 389-397, 2001.

3. Salaverria I, Perez-Galan P, Colomer D and Campo E: Mantle cell lymphoma: From pathology and molecular pathogenesis to new therapeutic perspectives. Haematologica 91: 11-16, 2006

4. Chen R, Chubb S, Cheng T, Hawtin RE, Gandhi V and Plunkett W: Responses in mantle cell lymphoma cells to SNS-032 depend on the biological context of each cell line. Cancer Res 70: 6587-6597, 2010.

5. Frick M, Dörken B and Lenz G: New insights into the biology of molecular subtypes of diffuse large B-cell lymphoma and Burkitt lymphoma. Best Pract Res Clin Haematol 25: 3-12, 2012.

6. Wang DL, Qi FH, Xu HL, Inagaki Y, Orihara Y, Sekimizu K, Kokudo N, Wang FS and Tang W: Apoptosis-inducing activity of compounds screened and characterized from cinobufacini by bioassay-guided isolation. Mol Med Rep 3: 717-722, 2010

7. Wang L, Raju U, Milas L, Molkentine D, Zhang Z, Yang P, Cohen L, Meng Z and Liao Z: Huachansu, containing cardiac glycosides, enhances radiosensitivity of human lung cancer cells. Anticancer Res 31: 2141-2148, 2011.

8. Gomes A, Bhattacharjee P, Mishra R, Biswas AK, Dasgupta SC and Giri B: Anticancer potential of animal venoms and toxins. Indian J Exp Biol 48: 93-103, 2010.

9. Qi F, Li A, Inagaki Y, Kokudo N, Tamura S, Nakata M and Tang W: Antitumor activity of extracts and compounds from the skin of the toad Bufo bufo gargarizans Cantor. Int Immunopharmacol 11: 342-349, 2011.

10. Qin TJ, Zhao XH, Yun J, Zhang LX, Ruan ZP and Pan BR: Efficacy and safety of gemcitabine-oxaliplatin combined with huachansu in patients with advanced gallbladder carcinoma. World J Gastroenterol 14: 5210-5216, 2008.

11. Meng Z, Yang P, Shen Y, Bei W, Zhang Y, Ge Y, Newman RA, Cohen L, Liu L, Thornton B, et al: Pilot study of huachansu in patients with hepatocellular carcinoma, non-small-cell lung cancer, or pancreatic cancer. Cancer 115: 5309-5318, 2009.

12. He X, Tang J, Qiao A, Wang G, Jiang M, Liu RH and Yao X: Cytotoxic biotransformed products from cinobufagin by $\mathrm{Mucor}$ spinosus and Aspergillus Niger. Steroids 71: 392-402, 2006.

13. Yeh JY, Huang WJ, Kan SF and Wang PS: Effects of bufalin and cinobufagin on the proliferation of androgen dependent and independent prostate cancer cells. Prostate 54: 112-124, 2003.

14. Takai N, Ueda T, Nishida M, Nasu K and Narahara H: Bufalin induces growth inhibition, cell cycle arrest and apoptosis in human endometrial and ovarian cancer cells. Int J Mol Med 21: 637-643, 2008

15. Wang J, Jin Y, Xu Z, Zheng $\mathrm{Z}$ and Wan S: Involvement of caspase-3 activity and survivin downregulation in cinobufociniinduced apoptosis in A 549 cells. Exp Biol Med (Maywood) 234: 566-572, 2009.

16. Zhang LLJ, Qian Y, Wang Y and Shen ZX: Cinobufacini induces the apoptosis of U937 cells and its mechanism. Tumor 27: 341-344, 2007.

17. Yang HYZN, Hong YW and Yu RX: The experimental research on cinobufacini inducing apoptosis in human leukemia cell line HL60. Fujian J Trad Chin Med 33: 43-44, 2002.

18. Qi F, Li A, Zhao L, Xu H, Inagaki Y, Wang D, Cui X, Gao B, Kokudo N, Nakata M, et al: Cinobufacini, an aqueous extract from Bufo bufo gargarizans Cantor, induces apoptosis through a mitochondria-mediated pathway in human hepatocellular carcinoma cells. J Ethnopharmacol 128: 654-661, 2010.

19. Carmeliet P and Jain RK: Angiogenesis in cancer and other diseases. Nature 407: 249-257, 2000.

20. Wang NYLS, Zhao W, Qin SK, Liu L and Chen HY: Study the effect of antiangiogenesis of arsenic trioxide in combination with cinobufacini on chick embryo choriallantoic membrane. Chin Clin Oncol 11: 864-866, 2006.

21. Tao WWX: Clinical observation of huachansu injection combined with CHOP regimen in treatment of NHL. J Med Forum 31: 89-93, 2010.

22. Zheng PSZY, Dai ZX, Ding XL and Sun XH: Effect of Huachansu injection on T-lymphocyte subgroups and natural killer cells in patients with non-Hodgkin lymphoma. Liaoning Trad Chin Med 37: 175-176, 2010.
23. Zheng B, Fiumara P, Li YV, Georgakis G, Snell V, Younes M, Vauthey JN, Carbone A and Younes A: MEK/ERK pathway is aberrantly active in Hodgkin disease: A signaling pathway shared by CD30, CD40, and RANK that regulates cell proliferation and survival. Blood 102: 1019-1027, 2003.

24. Han KQ, Huang G, Gu W, Su YH, Huang XQ and Ling CQ: Anti-tumor activities and apoptosis-regulated mechanisms of bufalin on the orthotopic transplantation tumor model of human hepatocellular carcinoma in nude mice. World $\mathbf{J}$ Gastroenterol 13: 3374-3379, 2007

25. Tempone AG, Pimenta DC, Lebrun I, Sartorelli P, Taniwaki NN, de Andrade HF Jr, Antoniazzi MM and Jared C: Antileishmanial and antitrypanosomal activity of bufadienolides isolated from the toad Rhinella jimi parotoid macrogland secretion. Toxicon 52: 13-21, 2008.

26. Cunha Filho GA, Schwartz CA, Resck IS, Murta MM, Lemos SS, Castro MS, Kyaw C, Pires OR Jr, Leite JR, Bloch C Jr, et al: Antimicrobial activity of the bufadienolides marinobufagin and telocinobufagin isolated as major components from skin secretion of the toad Bufo rubescens. Toxicon 45: 777-782, 2005.

27. Meng Y, Whiting P, Sik V, Rees HH and Dinan L: Ecdysteroids and bufadienolides from Helleborus torquatus (Ranunculaceae). Phytochemistry 57: 401-407, 2001.

28. Abdel-Aziz W, Jiang HY, Hickey RJ and Malkas LH: Ara-C affects formation of cancer cell DNA synthesome replication intermediates. Cancer Chemother Pharmacol 45: 312-319, 2000.

29. Mamelak AN and Jacoby DB: Targeted delivery of antitumoral therapy to glioma and other malignancies with synthetic chlorotoxin (TM-601). Expert Opin Drug Deliv 4: 175-186, 2007.

30. Fayette J, Coquard IR, Alberti L, Ranchère D, Boyle $H$ and Blay JY: ET-743: A novel agent with activity in soft tissue sarcomas. Oncologist 10: 827-832, 2005.

31. Erba E, Bergamaschi D, Bassano L, Damia G, Ronzoni S, Faircloth GT and D'Incalci M: Ecteinascidin-743 (ET-743), a natural marine compound, with a unique mechanism of action. Eur J Cancer 37: 97-105, 2001.

32. Simoens C, Korst AE, De Pooter CM, Lambrechts HA, Pattyn GG, Faircloth GT, Lardon F and Vermorken JB: In vitro interaction between ecteinascidin 743 (ET-743) and radiation, in relation to its cell cycle effects. Br J Cancer 89: 2305-2311, 2003.

33. Newman DJ and Cragg GM: Marine natural products and related compounds in clinical and advanced preclinical trials. J Nat Prod 67: 1216-1238, 2004.

34. Kanagal-Shamanna R, Lehman NL, O'Donnell JP, Lim MS, Schultz DS, Chitale DA, Bueso-Ramos CE, Medeiros LJ and Inamdar KV: Differential expression of aurora-A kinase in T-cell lymphomas. Mod Pathol 26: 640-647, 2013.

35. Shen H, Xu W, Luo W, Zhou L, Yong W, Chen F, Wu C, Chen Q and Han X: Upregulation of mdrl gene is related to activation of the MAPK/ERK signal transduction pathway and YB-1 nuclear translocation in B-cell lymphoma. Exp Hematol 39: 558-569, 2011.

36. Yin P, Wang Y, Qiu Y, Hou L, Liu X, Qin J, Duan Y, Liu P, Qiu $M$ and Li Q: Bufalin-loaded mPEG-PLGA-PLL-cRGD nanoparticles: Preparation, cellular uptake, tissue distribution, and anticancer activity. Int J Nanomed 7: 3961-3969, 2012.

37. Boatright KM and Salvesen GS: Mechanisms of caspase activation. Curr Opin Cell Biol 15: 725-731, 2003.

38. Rathmell JC and Thompson CB: The central effectors of cell death in the immune system. Annu Rev Immunol 17: 781-828, 1999.

39. Qi F, Li A, Inagaki Y, Xu H, Wang D, Cui X, Zhang L, Kokudo N, Du G and Tang W: Induction of apoptosis by cinobufacini preparation through mitochondria- and Fas-mediated caspasedependent pathways in human hepatocellular carcinoma cells. Food Chem Toxicol 50: 295-302, 2012.

40. Schrader A, Meyer K, von Bonin F, Vockerodt M, Walther N, Hand E, Ulrich A, Matulewicz K, Lenze D, Hummel M, et al: Global gene expression changes of in vitro stimulated human transformed germinal centre B cells as surrogate for oncogenic pathway activation in individual aggressive B cell lymphomas. Cell Commun Signal 10: 43, 2012.

41. Green MR, Aya-Bonilla C, Gandhi MK, Lea RA, Wellwood J, Wood P, Marlton P and Griffiths LR: Integrative genomic profiling reveals conserved genetic mechanisms for tumorigenesis in common entities of non-Hodgkin's lymphoma. Genes Chromosomes Cancer 50: 313-326, 2011.

42. Jiang Y, Zhang Y, Luan J, Duan H, Zhang F, Yagasaki K and Zhang G: Effects of bufalin on the proliferation of human lung cancer cells and its molecular mechanisms of action. Cytotechnology 62: 573-583, 2010. 